\title{
Effects of Climate Change on Pearl Millet (Pennisetum glaucum [L. R. Br.]) Production in Nigeria
}

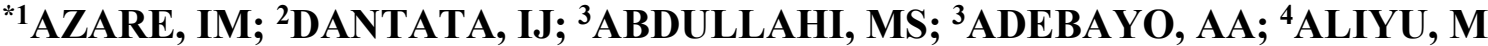 \\ ${ }^{*}$ Department of Environmental Science, Federal University, Dutse, Jigawa, State, Nigeria \\ ${ }^{2}$ Department of Agronomy, Federal University, Gashua, Yobe, State, Nigeria \\ ${ }^{3}$ Department of Soil Science, ${ }^{3}$ Department of Geography, Modibbo Adama University of Technology, Yola, Adamawa State, Nigeria \\ ${ }^{4}$ Department of Soil Science, Abubakar Tafawa Balewa University, Bauchi State, Nigeria \\ *Corresponding Author Email: isamagajiazare@gmail.com
}

\begin{abstract}
This paper attempts to examine the relationship between climate change and pearl millet production in Nigeria. It discusses the origin, distribution of the species with some of their properties including production constraints in the Sub Saharan Africa and Nigeria in particular. Northern states of Nigeria were found to be the dominant producers of pearl millets with Sokoto state having a total cultivated area of 747,580ha. Pearl millet was also found to be the major crop amongst others, useful for minimizing the adverse effect of climate change, hence facilitating income and food security among farming communities. Major production constraint of the crop in the Sub Saharan Africa, particularly in Nigeria is yield reduction and/or total crop failure caused by erratic seasonal rainfalls, floods, failing soil fertility and poor crop management practices. Biotic stress due to weeds such as Striga spp as well as insect pests and diseases pestilences is a constraint. Therefore, appropriate climate change mitigation efforts to improve pearl millet production and enhance food security should be adopted in the Sub Saharan Africa and Nigeria.
\end{abstract}

\section{DOI: https://dx.doi.org/10.4314/jasem.v24i1.23}

Copyright: Copyright $\odot 2020$ Azare et al. This is an open access article distributed under the Creative Commons Attribution License (CCL), which permits unrestricted use, distribution, and reproduction in any medium, provided the original work is properly cited.

Dates: Received: 30 November 2019; Revised: 20 December 2019; Accepted: 23 December 2019

Keywords: Climate change, pearl millet, Sub-Saharan Africa, Nigeria

Climate change and agriculture are interrelated processes, both of which take place on global scale. Global warming is projected to have significant impact on conditions affecting agriculture, including temperature, carbon dioxide, glacial run-off, precipitation and the interactions of these elements. The overall effect of climate change on agriculture depends on the balance of these effects. Assessment of the effects of global climate changes on agriculture might help to properly anticipate and adapt farming to maximize agricultural production (Azare, 2014). What has changed in the last few hundred years is the additional release of carbon dioxide by human activities, fossils and fuels burned to run cars and trucks, heat homes, businesses and power factories are responsible for about $98 \%$ of the U.S emission of carbon dioxide, $24 \%$ of methane and $18 \%$ of nitrous oxide (IPCC 2007; Azare, 2014).

Climate Change and Agricultural Production Systems: For the last 10,000 years we have been living in a remarkably stable climate that has allowed the whole of human development to take place. In all that time, through the mediaeval warming and the Little Ice Age, there was only a variation of $1^{\circ} \mathrm{C}$. Now we see the potential for sudden changes between 2 and $6^{\circ} \mathrm{C}$. We just do not know what the world is like at those temperatures. We are moving rapidly out of mankind's safe zone into new territories with no idea of adapting into them (Goodwin, 2008; Azare, 2014). There is growing evidence that climate change, specifically higher temperatures, altered patterns of precipitation and increased frequency of extreme events such as drought and floods, is likely to depress crop yields and increase production risks in many world regions (Bagamba et al., 2012). Generally, there are many factors influencing crop production and these include soil, relief, climate, pests and diseases among others. In relation to climate, rainfall is the dominant controlling variable in tropical agriculture since it supplies soil moisture for crops and grasses as fodder. Agriculture largely depends on climate to function. Hence, precipitation, solar radiation, wind, temperature, relative humidity and other climatic parameters affect and solely determine the global distribution of crops and livestock and their proclivity to higher yields or outputs (Ayoade,1983; Azare, 2014). These workers gave four ways in which climate affect agricultural production; changes in temperature and precipitation directly affect crop production and 
can even alter the distribution of agro-ecological zones; increased $\mathrm{CO}_{2}$ is expected to have a positive effect on agricultural production due to greater water use efficiency and higher rates of plant photosynthesis; runoff or water availability is critical in determining the impact of climate change on crop production, especially in Africa and agricultural losses can result from climate variability and the increased frequency of changes in temperatures and precipitation including droughts and floods (Kurukulasuriya and Rosenthal,2003; Azare, 2014). Projection by FAO (2005) and Azare (2014) shows that by 2100, Nigeria and other West African countries are likely to have agricultural losses of up to $4 \%$ due to climate change. Climate to some extent determines the choice of what plant to cultivate, how to cultivate it, the yields of crops and even the nature of livestock to keep. It can also be seen as one of the environmental factors that affects agricultural production. Supporting this, Ayoade (2002) confirmed that many of the problems facing agricultural productions are climate related. Climate change affect crops in a number of ways; these include growth process of crops, weeds, pests and diseases as early discussed. Crop growth is significantly affected by changes in $\mathrm{CO}_{2}$ concentration, temperature, moisture supply and severe weather. $\mathrm{CO}_{2}$ increase alone is expected to increase the productivity of annual crops, particularly those that may be limited by existing concentrations of carbon dioxide (i.e. most crops including wheat, rice, barley, cassava, potato and most trees). For these crops, increases in the order of 30 per cent would be expected for a doubling in $\mathrm{CO}_{2}$ if other changes in conditions remain constant. The increases would be less for plants that have a special $\mathrm{CO}_{2}$-concentrating mechanism (such crops as maize, millet, sugar cane, sorghum and many tropical grasses). The impact of climate changes since the $19^{\text {th }} \mathrm{C}$ is particularly evident today due to high average air and ocean temperatures, widespread melting of ice and snow around the world, increase global sea level as well as frequency and intensity of heat waves (World Bank, 2011; Azare, 2014). They further maintained that both floods and droughts are occurring more frequently and the interiors of continents have tended to dry out despite overall increase in total precipitation. Globally, precipitation has increased as the water cycle of the planet has speed up by warmer temperatures, even when the Sahel and Mediterranean regions have seen more frequent and intense drought. Heavy rainfalls and frequent floods have become more common, and there are evidences that intensities of storms and tropical cyclones have also increased. Climate change and agriculture are interrelated processes, both of which takes place on global scale. Global warming is projected to have significant impact on conditions affecting food crop agriculture, including temperature, carbon dioxide, glacial run-off, precipitation and the interactions of these elements. The overall effect of climate change on agriculture depends on the balance of these effects. Assessment of these effects helps to properly anticipate and adapts farming systems to maximize outputs (Wikipedia, 2011; Azare, 2014). Climate and agriculture being intricately connected is not a new phenomenon. Farmers and scientists have been trying to counteract the negative impacts of climate on food production for millennia. The prospect that climate change will increase global temperatures significantly and cause precipitation to be more unpredictable has recently put this millennium old struggle to maintain and increase global food security on the spotlight. Luckily, we have many policies and practices that have proven to work in the past and we can draw from them for future climate change action and policy (Natalia, 2011). The major agents of climate change have been ascribed to be increased levels of greenhouse gases (GHGs) beyond the natural limits due to uncontrolled activities such as burning of fossil fuels, increased use of refrigerants and agriculture which contributes GHGs through expansion of non-agricultural lands (e.g., forests) into agricultural lands (Maheswari et al., 2015).

Global Climate Change and Pearl Millet Production: Crop description: Pearl millet is the fifth most important cereal crop in the world after rice, wheat, maize, and sorghum. It is a widely grown rain-fed cereal crop in the arid and semi-arid regions of Africa and Southern Asia. In other countries, it is grown under intensive cultivation as a forage crop. Pearl millet is grown primarily for its grains on 26 million ha in the arid and semi-arid tropical regions of Asia and Africa (Rai et al., 2007; Gloria, 2013).

\begin{tabular}{lll}
\multicolumn{2}{c}{ Table 1: } & \multicolumn{2}{l}{ eading millet producing countries in the world } \\
\hline Rank & Country & Production (tones) \\
\hline 1 & India & $10,910,000$ \\
2 & Nigeria & $5,000,000$ \\
3 & Niger & $2,955,000$ \\
4 & China & $1,620,000$ \\
5 & Mali & $1,152,331$ \\
6 & Burkina Faso & $1,109,000$ \\
7 & Sudan & $1,090,000$ \\
8 & Ethiopia & 807,056 \\
9 & Chad & 582,000 \\
10 & Senegal & 572,155 \\
11 & World & $29,870,058$ \\
\hline Source: & worldatlas.com &
\end{tabular}

It accounts for almost half of global millet production, with $60 \%$ of the cultivation area in Africa, followed by $35 \%$ in Asian countries. European countries represent $4 \%$ of millet production and North America only 1\% mainly for forage. Global production exceeds 10 million tons per year. In Sub-Saharan Africa, pearl 
millet is the third major crop with the major producing countries being Nigeria, Niger, Burkina Faso, Chad, Mali, and Senegal amongst others (Table 1). In Southern Africa, maize has partially or completely displaced millet cultivation because of commercial farming (Basavaraj et al., 2010; Gloria, 2013).

The Pennisetum glaucum is the most widely grown type of millet. It has been grown in Africa and the Indian subcontinents since prehistoric times. The center of diversity, and suggested area of domestication, for the crop is in the Sahel zone of West Africa. Recent archaeon botanical research has confirmed the presence of domesticated pearl millet on the Sahel zone of northern Mali between 2500 and 2000 BC. Cultivation subsequently spread and moved overseas to India. The earliest archaeological records in India dated to around $2000 \mathrm{BC}$, and it spread rapidly through India reaching South India by 1500 BC, based on evidence from the site of Hallur. Cultivation also spread throughout eastern and southern Africa. Records exist for cultivation of pearl millet in the United States in the 1850s, and the crop was introduced into Brazil in the 1960s, Agro - Ecosystem Analysis (AESA, 2014).

Origin: Pearl millet originated in tropical western Africa some 4000 years ago (Fig. 1). The greatest numbers of both wild and cultivated forms of this species occur in this region. From there, it differentiated into globosum race and moved to the western side, and it also differentiated into the typhoides race that reached eastern Africa and spread to India and southern Africa some 2000-3000 years ago (Khairwal et al.,2007)

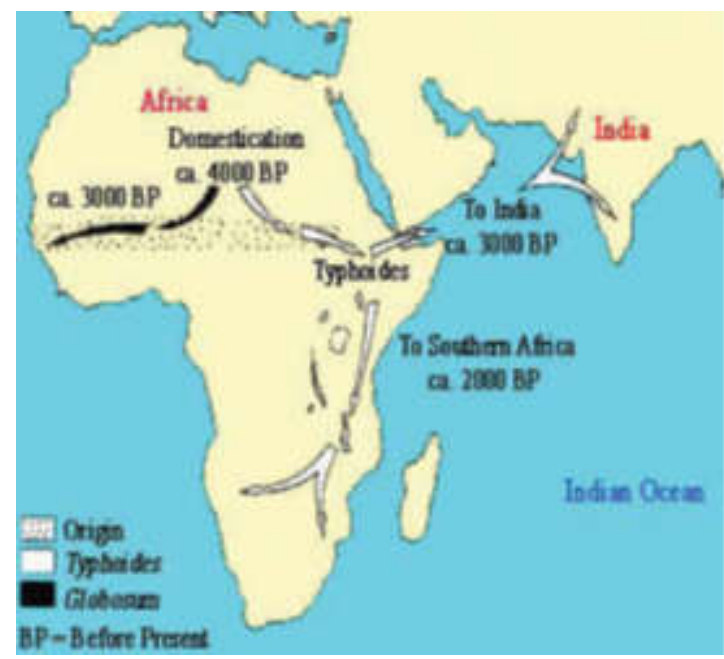

Fig.1: Map of pearl millet domestication in tropical W/Africa. Source: Khairwal et al. (2007)
Distribution: Area and production of pearl millet in the world is combined with other species like finger millet, so, separate data for pearl millet are not available. However, pearl millet is cultivated mostly in Africa (about 14 million ha) and Asia (about 12 million ha). In Asia, India has the largest area of 10 million ha and accounts for about $50 \%$ of the total area under all millets in the world. Sixty percent of world millet area is in Africa. Asian countries occupy 35\% of world millet area. European countries cover $4 \%$ of millet area and $1 \%$ is in North America. The developing countries in Asia and Africa contribute about $93 \%$ of total millet production in the world. Asia alone contributes $43 \%$ of world millet production; European countries produce $6 \%$ and North America produces approximately 1\% (Khairwal et al., 2007). Climate change affects crop production through direct impacts on the biophysical factors such as plant and animal growth and infrastructures associated with food processing and distribution (Schmidhuber and Tubiello, 2007)

Pennisetum glaucum (Plate 1) is supremely adapted to heat and aridity and, for its entire current decline, seems likely to spring back as the world gets hotter and drier. Perhaps the best of all "life-support" grains, pearl millet thrives where habitats are harsh. Of all the major cereals, it is the one able to tolerate extremes of heat and drought (Lost Crops of Africa, 1996).

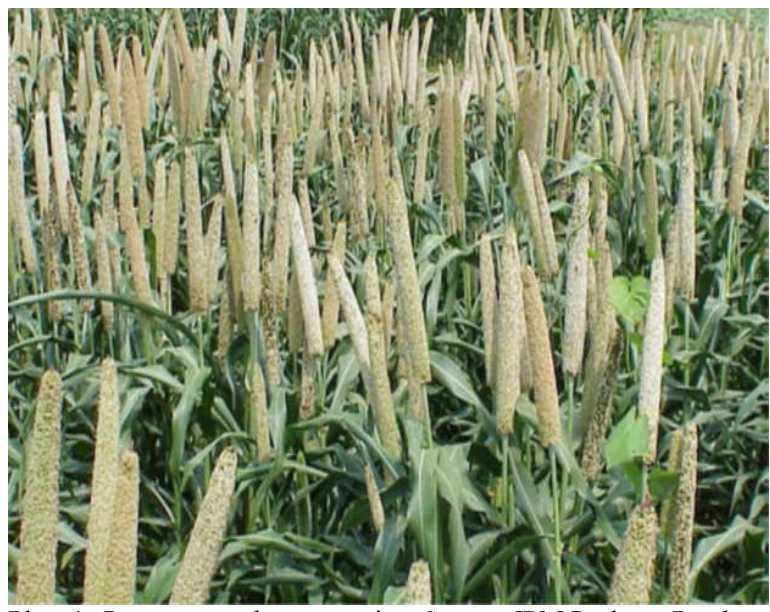

Plate 1: Pennisetum glaucum variety Source: IPM Package-Pearl Millet (2014)

Sub-Saharan Africa: Global agriculture is facing the probable impact of global warming. Recent studies suggest that the production of major commodities has declined since 1980 due to global warming (Lobell et al., 2011; Harold, 2015). It is estimated that, given current warming trends in sub - Saharan Africa, the production of major cereals could decline by as large as $20 \%$ by mid -century (Schlenker and Lobell, 2010; Harold, 2015). Africa has been identified as one of the 
parts of the world most vulnerable to the impacts of climate change (IPCC, 2014; Niang et al., 2014; Olivia et al., 2016). Sub-Saharan Africa is a rapidly developing region of great ecological, climatic and cultural diversity (NASAC, 2015; Olivia et al., 2016). The agriculture sector employs $65 \%$ of Africa's labor force and the sector's output has increased since 2000, mainly due to an expansion of agricultural area (World Bank, 2013). Agricultural production in Sub-Saharan Africa is particularly vulnerable to the effects of climate change, with rain fed agriculture accounting for approximately $96 \%$ of overall crop production (World Bank, 2015a; Olivia et al., 2016). In Africa, there are estimated 14 million hectares of millet in the zone, making it the third most widely grown crop in sub-Saharan Africa. The crop was probably domesticated some 4,000-5,000 years ago along the southern margins of the central highlands of the Sahara shown in Figure 1 above, has since become widely distributed across the semiarid tropics of Africa and Asia. Today, approximately one-third of the world's millet is grown in Africa with about 70 percent of it in West Africa. Millet biodiversity constitutes both a unique ecological heritage and a critical food security component among millions of small-scale farmers. In particular, pearl millet and the West African millets have a superior adaptation to drought and poor soils, providing a reliable harvest under such conditions, growing where no other crops succeed, requiring minimal inputs, and providing good nutritional sources (Joseph, 2001). Pearl millet is highly adapted to drought, representing an essential component of the food security and livelihoods of many million poor farmers that inhabits dry lands and semi-arid areas throughout Sub-Saharan Africa (Joseph, 2001).

Climate Change and Pearl Millet in Nigeria: Nigeria's climate is also likely to see growing shifts in temperature, rainfall, storms and sea levels throughout the $21^{\text {st }} \mathrm{C}$. These climatic challenges, if unaddressed, could throw already stressed resources such as land and water into even shorter supply. Moreover, poor responses to resource shortages could have serious negative secondary effects, including more sickness and hunger, fewer jobs, and poor economic growth, which in turn could open the door to more violence. (Aeron, 2011). Available evidence also shows that climate change has impacted on agriculture and health in Nigeria (Adefolalu, 2007; Azare, 2014). The decrease in rainfall, increasing temperature and evapotranspiration have resulted in either reduction of water levels or total dry up of some rivers and lakes in Northern Nigeria, while lake Chad in Nigeria is reported to be shrinking in size at an alarming rate since the 1970s, Suleiman (2014). In the coastal region of Nigeria, Sea level rise of $0.2 \mathrm{~m}$ and incursion of salt water into the coastal plain for about $2016-3400 \mathrm{~km}^{2}$ was reported, (Nwafor, 2006; Azare, 2014). Millet is an important crop in terms of production and consumption in Northern Nigeria, where it is mainly produced (Agboola, 1979; CBN, 2001; Abdullahi et al., 2006). Its production is undermined and yield is always made un-certain due to occurrence of drought. The dominant millet species grown in Nigeria is pearl millet, which is classified into three types: the early maturing Gero is the most widespread and cultivated in the Southern and Northern Guinea savanna areas as well as in the Sudan savanna and Sahel zones. Maiwa and Dauro types are late maturing and are mostly grown in the southern and northern Guinea savanna area (Usman et al., 2014). Pearl millet has been cultivated for centuries in difficult crop production environments and man-disturbed habitats around the world owing to its resilient nature and ability to withstand harsh climatic conditions (explained above). In addition to low water requirement, pearl millet is particularly adapted to drought prone regions, regions with poor soil fertility and hot/dry climates as in the case of sub- Saharan Africa and parts of Asia. A deep root system coupled with a short life cycle enables pearl millet to be grown in areas with low rainfall, ranging from 200 to $600 \mathrm{~mm}$ (Panaud, 2006; Jukanti et al., 2016). Drought stress during flowering through grain filling results in low and unstable yields (Wilson, 2011; Gloria, 2013). According to (Yadav, 2010; Gloria, 2013) it was pointed out that post flowering drought stress is one of the most important environmental factors reducing pearl millet grain yield as much as $70 \%$. Too much rainfall at flowering can also cause crop failure (Oushy, 2010; Gloria, 2013).

Peal millet production constraints: The main challenges to millet production in Africa are declining yields, which are mainly due to short and unreliable rainy seasons with frequent dry spells, droughts, declining fertility of soils and poor crop management. The yields of millet range between 500 and 1500 $\mathrm{kg} / \mathrm{ha}$, but can be as low as $150 \mathrm{~kg} / \mathrm{ha}$. The low yields are also partially due to the crop's low harvest index (less than 20\%), cultivation on poor soils with no or very little inputs, millet production is declining due to the switch by farmers (and consumers) to other cereals such as maize, inadequate support to millet promotion from a research and policy point of view in many African countries, devastating pests and diseases attacks can also occur. The Africa Organic Agriculture Training Manual [AOATM] (2013) and Maryam et al. (2017) reported that major constraints to production across all the districts were low soil fertility, Striga, downy mildew and high labour costs. Usman et al. (2014) added low and erratic rainfall, high soil and air 
temperatures and biotic stresses. Genetic enhancements successes in millet which interplays with several other factors such as availability of genetic resources, inheritance and stability of the traits desired to be improved, simplicity and effectiveness of techniques with reliability and cost effectiveness and access to test environments are also important constraints. In drier and in areas with marginal rainfall for example, drought is the most devastating constraints that can occur at any growth stage in pearl millet. Rai et al. (1999) report that post flowering, that is to say, terminal or end of season drought stress is of greater significance and is much better understood than pre-flowering stress in pearl millet. Mahalakshmi and Bidnger (1985) pointed out that crop growth that occurs during the post flowering period have been demonstrated to be the most sensitive to water deficits. The terminal drought has been shown to reduce grain yield by 40 - $49 \%$ with large variation among varieties (Fussel et al., 1991). Panicle threshing percentage under stress condition is a good indicator of terminal drought tolerance in pearl millet. In conjunction with grain yield potential and earliness, it accounts for greater than $80 \%$ of the variety variation in grain yield under terminal drought stress (Bidinger and Mahalakshmi, 1993). However, published information confirming the existence of adequate variability for drought tolerance parameters are not in abundance. Pearl millet downy mildew caused by Sclerospora graminicola has also been a serious production constraint. Studies on physiological limits of pearl millet yield in West Africa showed that due to high temperatures, the duration of the grain-filling phase is short between $20-25$ days. This limits the amount of light that can be absorbed and transformed into biomass for grain development. In West African pearl millets, the stem remains green until grain maturity. Stem weight does not decrease in favour of grain filling. Taking the equation proposed by Monteith cited in Bello (2012). Consequently, grain yield relies on soil water reserves during grain filling. But photosynthesis consumes a great deal of water; as a minimum of $250 \mathrm{~g}$ of water per gram of dry matter produced. The biomass available to fill grains will thus be $4 \mathrm{t} /$ ha as a maximum grown in heavy soils. Without irrigation, the physiological grain yield limits in the savannah zone will thus be about $4 \mathrm{t} / \mathrm{ha}$. Water deficit and temperature extremes influence there productive phase of plant growth. It was described that the flower initiation and inflorescence is badly affected by the water stress in cereals. Similarly, if the temperature increases of about $30^{\circ} \mathrm{C}$ during floret development it can cause sterility in cereals (Ali et al., 2019).

Conclusion: Pearl millet is one of the most important cereal crops in the world. It was domesticated more than 4,000 years ago in the heart of Sahara and spread widely to East Asia and India. Cultivated on 14 million ha in Africa and likewise in Asia. Pearl millet is also produced in the Northern parts of Nigeria and Sokoto state is the largest producer. The crop provides both food and income security to the populace. Climate change adversely affects production of millet due to drought, flooding and heat stress to cause total crop failure of millets in Nigeria. Therefore, appropriate climate change mitigation efforts should be adopted in prone areas to improve pearl millet production and enhance food security.

\section{REFERENCES}

Abdullahi, AB; Iheanacho, AC; Ibrahim, A; (2006): Econometric Analysis of the Relationship between Drought and Millet Production in the Arid Zone of Nigeria: A Case Study of Borno and Yobe States. Journal of Agriculture and Social Science. Pp.170-174

Aeron, S; (2011). Climate change Adaptation and Conflict in Nigeria. A Special Report by the United States Institute of Peace. 2301 Constitution Ave, NW • Washington, DC 20037. Pp. $1-16$

AESA (2014). Agro - Ecosystem Analysis Based IPM Package-Pearl Millet Department of Agriculture and Cooperation Ministry of Agriculture, India. Pp. 1 - 51

Ali, R; Ali, R; Sundas, SM; Xilling, Z; Xuekun, Z; Yan, LV; Jinsong, X; (2019). Impact of Climate Change on Crops Adaptation and Strategies to Tackle Its Outcome: A Review. Plants 2019, 8, 34

AOATM (2013). A Resource Manual for Trainers. Module 09 Crops: Unit 3 Millet, Draft Version 2.0 March 2013. Pp. $1-26$

Azare, IM; (2014): Farmers' Perception and Response to Climate Change in Katagum Local Government Area of Bauchi State. MSc. Unpublished Thesis. Pp. 1 -85.

Bagamba, F; Bashaasha, B; Claessens1L; Antle, J; (2012): Assessing Climate Change Impacts and Adaptation Strategies for Smallholder Agricultural Systems in Uganda. African Crop Science Journal, Vol. 20, Issue Supplement s2, pp. $303-316$.

Bello, D; (2012). Precipitation effectiveness indices and millet yield in two local governments areas of Kano state, Nigeria. Unpublished Thesis 
submitted to the school of Postgraduate Studies, Ahmadu Bello University, Zaria. 82pp.

Bidinger FR; Mahalakshmi V; (1993). Selection for drought tolerance in the 1992 Annual reports on cereals programme of the International Crops Research Institute for Semi-Arid Tropics (ICRISAT), ICRISAT, Pantancheru, India pp 57 -59 .

Fussel, IK; Bidinger FR; Bider P; (1991). Crop physiology and breeding for drought Resistance, research and Development. Field Crops Research, 27: 183-199.

Gloria, C; (2013). Genetic Characterization of Pearl Millet (Pennisetum Glaucum (L.) R. Br.) Genotypes in Zambia. Unpublished MSc. Dissertation Submitted to the University of Zambia. Pp. $1-103$

Harold, M; (2015). Cereal Crops: Rice, Maize, Millet, Sorghum, and Wheat. A paper presented at Abdou Diouf International Conference Center. Dakar, Senegal 21 - 23 October, 2015.

Joseph AG; (2001). Review of the African millet diversity. FAO - Food and Agriculture Organization of the United Nations. Paper for the International workshop on fonio, food security and IPGRI / IFAD, Bamako, Mali, 19-22 November 2001. livelihood among the rural poor in West Africa.Pp. 1- 9.

Jukanti AK; Laxmipathi, CL; Gowda, Rai KN; Manga, VK; Bhatt RK (2016). Crops that feed the world 11. Pearl Millet (Pennisetum glaucum L.): an important source of food security, nutrition and health in the arid and semi-arid tropics. Springer Science+Business Media Dordrecht and International Society for Plant Pathology 2016.

Khairwal, I S and Rai, K N and Diwakar, B and Sharma, Y K and Rajpurohit, B S \& Nirwan, B \& Bhattacharjee, R (2007). Pearl Millet Crop Management and Seed Production Manual. Patancheru 502 324, Andhra Pradesh, India: International Crop Research for Semi-Arid Tropics. Pp. 104.

Lost Crops of Africa: Grain Vol. 1 (1996): Board on Science and Technology for International Development National Research Council. National Academies Press, Publishers. Available at http://www.nap.edu.
Mahalakshmi V. and Bidinger F. R. (1985). Water stress and time of floral initiation in pearl Millet. Journal of Agricultural Sciences, 105: 237 - 239.

Maheswari, M; Sarkar, B; Vanaja, M; Srinivasa Rao, M; Srinivasa Rao, Ch; Venkateswarlu, B; Sikka, AK' (2015). Climate Resilient Crop Varieties for Sustainable Food Production under Aberrant Weather Conditions. Central Research Institute for Dryland Agriculture (ICAR), Hyderabad. P47.

Maryam AD; Ignatius IA; Pangarayi BT; Kwadwo O; John SY; Eleblu; Beatrice EI; (2017). Farmers' Production Constraints, Knowledge of Striga and Preferred Traits of Pearl Millet in Jigawa State, Nigeria. Global J. Sci. Frontier Res.: D Agriculture and Veterinary 17 (3) Versions 1.0

Natalia, T; (2011). Climate Change Current Issues. Kiel Institute for the World Economy Hindenburgufer 6624105 Kiel, Deutschland. Pp $1-29$

Olivia S; Sophie A; Florent B; Dim C; Alexander R;William H; Michiel S; Mahe' P; Julia R; (2016). Climate change impacts in Sub-Saharan Africa: from physical changes to their social repercussions. (15)8. 1436-3798.

Rai K. N., Murty D. S., Andrews D. J. and Bramel-cox P. J. (1999). Genetic enhancement of Pearl millet and sorghum for the semi-arid tropics of Asia and Africa. Genome, 42: 617 - 628.

Schmidhuber, J; tubiello, FN; (2007): Global Food Security under Climate Change. Proceedings of National Academy of Sciences of the United States of America. 104 (50). 19703 - 19708.

Suleiman, IL; (2014). An Appraisal of Climate Change and Agriculture in Nigeria. Journal of Geography and Regional Planning. 7(9). 176 184.

Usman, YM; Hussaini, M; Baba, MB; Sherif f, B; (2014): Effect of Different Tillage Methods on the Growth and Yield of Pearl Millet under Rainfed Conditions. The International Journal of Science \& Technoledge. 2 (11). $62-67$

World Bank (2013). Kenya-towards a water secure Kenya: water resources sector memorandum. Report No 28398-KE. World Bank, Washington, $\mathrm{DC}$ 